Article

\title{
Experimental and Creative Approaches to Collecting and Distributing New Media Art within Regional Arts Organisations
}

\author{
Georgia Smithson \\ The Faculty of Arts and Creative Industries, The University of Sunderland, Sunderland SR1 3SD, UK; \\ georgia.smithson@research.sunderland.ac.uk
}

Received: 6 May 2019; Accepted: 3 July 2019; Published: 5 July 2019

\begin{abstract}
This article is an overview of preliminary research undertaken for the creation of a framework for collecting and distributing new media art within regional art galleries in the U.K. From the 1960s, artists have experimented using computers and software as production tools to create artworks ranging from static, algorithmic drawings on paper to installations with complex, interactive and process-oriented behaviours. The art-form has evolved into multiple strands of production, presentation and distribution. But are we, as collectors, researchers, artists and enthusiasts facing an uncertain future concerning the integration of new media art into institutional cultural organisations? Recently, concerns have been raised by curators regarding the importance of learning how to collect new media art if there is to be any hope of preserving the artworks as well as their histories. Traditional collections management approaches must evolve to take into account the variable characteristics of new media artworks. As I will discuss in this article, although regarded as a barrier to collecting new media artworks, artists and curators at individual institutions have recently taken steps to tackle curatorial and collections management activities concerning the often unpredictable and unstable behaviours of new media artworks by collaboration and experimentation. This method has proved successful with some mainstream, university and municipal galleries prior to acquiring or commissioning new artworks into their collections. This paper purports that by collaboration, experimentation and the sharing of knowledge and resources, these concerns may be conquered to preserve and make new media art accessible for future generations to enjoy and not to lament over its disappearance.
\end{abstract}

Keywords: new media art; collecting; documentation; distribution; access; collaboration; experimentation; innovation; networks

\section{Introduction}

The introduction of the catalogue that accompanied the pioneering Cybernetic Serendipity international exhibition from 1968, curated by Jasia Reichardt, reveals how far technology has progressed in almost fifty years: 'Cybernetic Serendipity deals with possibilities rather than achievements, and in this sense is prematurely optimistic. There are no heroic claims to be made because computers have so far neither revolutionised music, nor art, nor poetry, in the same way that they have revolutionised science' (Reichardt 1969). However, those 'possibilities' noted by Reichardt have evolved into achievements and mobile technology that could only be imagined and portrayed in the context of science fiction all but fifty years ago; the use of computers and networks has allowed for mass distribution and seemingly endless possibilities.

Art critic and curator, Domenico Quaranta, argues that the 'new' in 'new media art', is traceable back to the 1960s, and what was once defined as 'computer art', is still relevant and meaningful today. 
'... it is the art that uses new media technologies as a medium- period. No further complexity is admitted' (Quaranta 2012). In the context of a medium-based definition of new media art, curator, Christiane Paul, reasons the label assigned to this broad range of practices and artistic works as 'The lowest denominator for defining new media art seems to be that it is computational and based on algorithms' (Paul 2008). The term has come to encompass artworks that curator, Steve Dietz, identified as having three specific characteristics of connectivity, interactivity and computability and where the artist can intentionally focus on the process rather than the finished product. He also recognises that traditional art museum categorisations for documentation purposes are not always suitable for new media artworks. Furthermore, new media platforms can be utilised for the promotion, presentation and distribution of new media artworks affording a huge audience reach (Deviantart, rhizome.org, Olia Lialina's artteleportacia.org). According to statistics website Statista.com, it is projected that by 2020 there will be almost three billion users of social media creating global media culture, whether that be sharing images, blogs, music or art online. But what would happen to this ongoing documentary of the world community if social media sites decided to call it a day or Google ceased to exist? The thought process, artworks, documentation and reviews of artistic creations and collaborations would be lost, unless they were stored on a hard drive or memory stick in the possession of a collector (either accidently or purposefully).

When we consider the length of time new media art has been practiced, why then is it not common place for works to be found in collecting institutions? The purpose of this research is to necessitate change around the commissioning and collecting of new media art within small, regional art galleries where collecting remits are in need of updating to ensure engagement with an increasingly media saturated audience and to initiate integration with the existing collection. As Natalie Kane, curator of Digital Design at the Victoria \& Albert Museum argues, 'institutions are by nature ill-equipped to understand the nature of digital work' (Kane 2018). Christiane Paul backs up Kane's argument by stating 'because of its characteristics, the digital medium poses a number of challenges to the traditional art world, not least in its presentation, collection and preservation' (Paul 2015). She also notes this in the context of the exhibition space being mainly a 'white cube' model rather than being a space suited to flexible installation and technology requirements.

Although it is generally acknowledged that the medium does pose numerous challenges to curators and exhibition staff, through the collaborative work of researchers and curators such as Beryl Graham and Sarah Cook, co-founders of CRUMB (Curatorial Resource for Upstart Media Bliss), forward thinking curators Steve Dietz and Christiane Paul, artists Cory Archangel and Casey Reas and arts organisations, such as the Victoria \& Albert Museum and the Guggenheim, there is an awareness of new media art within contemporary and traditional art organisations which has led to experimental models of curation and collecting. For example, in 2010, the innovative, collaborative project Current: an experiment into collecting Digital Art was initiated by the Harris Museum and Art Gallery, a municipal gallery in Preston, UK, which I will discuss and examine later in this paper. As Graham accurately points out 'One of the significant differences between new media and other kinds of art is that the same set of new media are used for both the art itself and the interpretation, exhibition or collections management' (Graham 2016). These notable differences can be a cause of concern for the purposes of documentation to preserve the artworks' longevity. This could be due to the ephemeral nature of some new media artworks, the documentation being integral to the artwork and the artwork being confused with the interpretation tool. However, research undertaken by organisations such as the Variable Media Network which emerged from the Guggenheim Museum's efforts to strategise the preservation and associated activities of curation of its new media art collection aim to combat these concerns. The intention is ' ... to establish a process and means to address artworks created across a variety of media and materials, to determine protocols and initiatives that will bring a flexible approach to the preservation of a range of creative practices' (Depocas 2003).

After considering acknowledged key issues of curatorial activities associated with new media art, this paper will examine the experimental and alternative models of collecting, documenting, 
distribution and preservation from an interdisciplinary perspective, by mainstream and grassroots organisations, with the intention of banishing the myths that it is problematic, costly and unworthy of collecting. Cultural institutions cannot afford to ignore new media art as it will alienate their future, technical-savvy visitors and curb the reach of their virtual audience. Although some municipal, university and mainstream institutions seem to struggle with even the subject of new media art, artists and some curators are finding ever more innovative ways of creating, collecting, documenting and distributing artworks by trial and error which will be discussed in further detail. Artists are aware of their audience demographic and take advantage of the often free, digital and online channels and platforms available. Occasionally even the distribution is an integral concept of the artwork. In order to understand the integral components that the curation of new media art entails, I will break them down into four sections for the purpose of this paper: Distribution, documentation, preservation and collecting. I intend to do this by examining experimental models that have gone on to be employed by various organisations and artists alike.

The University of Sunderland secured an Arts and Humanities Research Council and Northern Productivity Investment Fund studentship award in 2017 for a researcher to investigate new, cost effective models for collecting and distributing new media art with the partner organisation being Northern Gallery for Contemporary Art. NGCA is a small regional gallery in the North East of the U.K. with a focus on commissioning and exhibiting while collecting works from exhibiting artists. NGCA will stand to benefit from this research with the aim of developing distribution networks, keeping costs to a minimum, and a clear collecting remit written within the collections development policy. By researching current curatorial models and practices and understanding the reasons why the collection of new media art is not as widespread as with that of traditional art forms the aim of the research is to assimilate data on the currently disparate curatorial activities to produce a framework for use in a regional gallery setting. Experiments, in this context, will be carried out on existing artworks within the collection on how they marry with current and new documentation approaches. By working with artists from the concept stage to production will provide a greater understanding of how they intend their artworks to be exhibited and preserved for the future.

\section{Curatorial Key Issues}

Factors that raise concerns prior to addressing outdated collecting remits and Collections Development Policies specific to new media art within regional galleries include:

- Conservation

- Maintenance

- Obsolescence of technology

- Taxonomy

- Classification

- Museum practice versus artistic ideals

It is accepted that the characteristics and behaviours of new media art can be many and varied, unpredictable, surprising and challenging to work with. The rethinking of curatorial activities has been examined by Graham and Cook, (2010) Rethinking Curating: Art After New Media, Ippolito and Rinehart, (2014) Re: Collection, Art, New Media and Social Memory, Paul, (2003) Digital Art and Hope, C. and Ryan, J.C., (2014) Digital Arts: An Introduction to New Media. While Graham and Cook view the challenges as opportunities to rethink curatorial practices and explore the characteristics peculiar to new media art, Ippolito and Rinehart investigate three threats to preservation: technology, institution and law, and calculate how each can assist in preservation rather than destruction.

\subsection{Distribution}

With so many diverse and distinct methods of distribution, it could be considered that the way in which artworks are made accessible is part of the making process and central to the artworks' 
integrity. Through the course of research undertaken so far, creative and cost-effective models have been identified, such as the MulengaMojis which digital artist Emily Mulenga employs. This model takes up no physical space-an important factor for an emerging artist as it is cost- free (ironically, her 2017 Firstsite exhibition was titled Taking Up Space). She makes her new artworks accessible for one hour to allow collectors to download using Vimeo, Drop Box and Weshare. Does this limit the reach or make them more attractive to collect as they have a limited availability?

Another economical approach of distribution is operated by little man, based in Liverpool, U.K. who borrows space for non-exhibitions. That is to say that artist exhibitions are installed, documented and taken down in a single day without ever opening to the public, they can only be viewed through the littlemangallery.com website or by using Instagram. Created by Gabrielle la Puente and Michael Lacey, little man allows artists and curators to develop their practice in an exhibition context without burdening themselves with the logistics of accessing and opening spaces. Their belief that engaging with art online is now common practice and that many art enthusiasts view exhibitions on the internet as opposed to physically visiting these exhibits, thus making the artworks more accessible and affording a larger audience reach. This in itself finds artists most engaged and supported by their audience within their social media following. Cynically this could be perceived as giving up on the physical art experience. Or is it making the artist and their work more accessible when they would not have ordinarily been given the opportunity to stage a physical exhibition? This model allows for a high turnover of artworks to be displayed and thus made accessible.

Due to the little man model's advantage of quick and logistically light installation, programming for a similar model within the physical gallery space at Northern Gallery for Contemporary Art is being undertaken, where an audio visual 'drum' or viewing module can be utilised for the display of one artwork at a time. As it has multi-purpose functionalities for viewing AV works and pre-installed projection equipment, NGCA has the advantage of quick installation. The aim is to make new media artworks from the NGCA collection accessible for short periods of time with supporting publicity using their social media platforms of Facebook, Twitter, Instagram, Flickr and YouTube, while considering the reproduction rights of the artist. Some artists are open to their works being publicised using these platforms but there is a risk that the works can be manipulated and then distributed while the original intent of the artist is lampooned, or completely diminished. The MulengaMoji model will be considered with the intention of making the artworks from the collection accessible to an online audience. Engagement will be captured and analysed to assess its suitability for the distribution of artworks from the NGCA collection.

Following on from accessing artworks digitally, the s[edition] platform allows users to create a collection using digital editions, which they compare to a 21st century version of silk screen and woodcut printing. Any digital display device can be used for display. Similar to physical art, the artworks can be sold on to other collectors using the Trade platform. A Tracy Emin edition can be purchased for $£ 62.00$ making the artworks accessible to collectors with limited funds. s[edition] have gone to great lengths to establish fixed rules and practices to ensure a fair-trading platform. For example, collectors are not free to do with the artwork as they wish. It cannot be downloaded further; it must be streamed to the application only which does raise questions and concerns of ethics and authenticity where networked and digital distribution is employed. How far can the artwork be replicated? Can it be altered? Artists such as Corey Arcangel positively encourage the replication, modification or manipulation of their works while others such as Phil Collins insist on the exact specifications of display and situation as originally prescribed by him, the artist. While some believe it to cheapen the integrity and monetary value of their work, for others, distribution is an integral component of their work: Seth Price, in his artwork Dispersion (2002), which takes the form of an historical essay, considers that there must be evidence or knowledge of an artwork in order for it to be considered art, therefore without a method or methods of presenting to an audience, how could an artwork be classified as such without ever being viewed? 
The Museum of London recently ventured into a new model of exhibition distribution by collaborating with London-based grassroots art collective further field. The 2017-2018 exhibition City Now, City Future staged at the Museum was the result of a collaborative project with furtherfield whose focus is on arts and media community involvement projects. By working reciprocally with an organisation who have the relationships, tools and knowledge in place to distribute artworks digitally, the Museum of London benefitted as they reached a new audience rather than that of the physical museum visitor or snippets of the exhibition being uploaded to the institution website. Furtherfield also promote knowledge distribution between institutions by working with a new stream of curators who then go on to work in mainstream institutions. From a researcher's perspective, it would be interesting to investigate the effect this has on the modes of curation of mainstream institutions as to whether the new curators with 'grass roots' training use their experience to engage with an audience not usually connected with a more 'formal' organisation. When compared to the training fledgling curators experience when working with organisations such as furtherfield, commercial gallery owner, Jonathan Carroll states that he sells to the art institutions which tend to be more adventurous in their approach to collecting. He also acknowledges that the approach of some institutions has changed dramatically. He credits this to the new tranche of institutional curators who have grown up with digital technology and art and therefore a natural choice for new acquisitions.

The most prevailing form of distribution by institutions is by the use of an online database. An excellent example of this can be found at the V\&A website which feature images and full documentary records of each artwork. This is followed by collaborative projects between institutions and organisations such as furtherfield and The Museum of London project or the Harris Museum and Art Gallery experiment which will be examined later in this article. Loaning artworks out to other institutions where the building has the correct environmental conditions and security measures in place also ensure artworks become accessible by a wider audience. The Stedelijk Museum, Amsterdam, is currently researching ways into making the collections accessible by the use of new mobile media. While this appears to be a relatively new experiment for institutions, artists already employ these sustainable and far-reaching methods. Institutions may take note of artists like Emily Mulenga and her MulengaMojis from 2012 to experiment with innovative distribution methods by the use of new media.

The new media art world has many emerging artists, therefore regional galleries with modest budgets can give 'first showings' and buy cheaply (for example, NGCA afforded Cory Arcangel his first single, UK show in 2007). Software-based artworks can easily be distributed or loaned out. This ease of mobility allows for international networks to be established and utilised to the benefit of the gallery and artist alike.

\subsection{Preservation Strategies}

As discussed, the collecting of new media art raises a range of concerns and the responsibility of maintaining it may be one of the main challenges. One of the anxieties of curators is how to preserve not only the artwork which can be process-oriented, time-based and networked, but the ever-evolving hardware that is integral to the work. As Andrea Lissoni, Senior Curator of International Art (Film) at Tate, illustrates: 'In a digital landscape the environment is made of data, and how we preserve these data is a big question. This is going to be a big challenge, because so many works are now conceived as a part of something that changes' (Tate 2015).

To try and combat the 'big challenge' addressed by Lissoni, experimental preservation techniques are being tried and tested by means of case studies on artworks belonging to the Guggenheim Collection by the Variable Media Network. To understand the needs of each artwork, each physical component becomes a case study which is broken down into four main strategies of preservation:

- $\quad$ Storage and collecting (hardware)

- Emulation (recreation of operation systems- NOT the artworks itself)

- Migration (is it possible to present on an alternative platform?)

- Reinterpretation (is it possible to transfer to an alternative technological framework?) 
The approach invites creators to imagine how an artwork might be translated into a new medium in the future once its current medium expires and to define their work independently from the medium, thus promoting the longevity of the artwork. The migration and reinterpretation strategies could prove problematic, as the original intent of the artist must be carefully considered. As Bernhard states in his 2013 publication (the results of the digital art conservation project that was conceived at the Centre for Arts and Media, (ZKM) Karlsruhe, Germany, Preservation of Digital Art: Theory and Practice warns: "And neither should the works be "improved" technically or aesthetically. They should retain their original work character, behaviour, and aesthetics for as long and as faithfully as possible, and in doing so be testimony to the epoch and the conditions in which they were created' (Serexhe 2013). By testing and sharing the results of artworks with varying behaviours, comparisons can be made against those with similar behaviours to promote a future for artworks not previously tested in this way. This demonstrates that although the solution to preservation appears at first complex and daunting, by working methodically through each issue, solutions can be found and documented for future use. By working alongside the creator or artist, museum and media professionals can imagine potential futures for artworks to successfully be integrated into a collection using tried and tested methods.

\subsection{Documentation}

Archival specialist, Annet Dekker, sums up the position most curators are faced with in her 2014 paper Assembling traces, or the conservation of net art: 'Artists and museums are trying to document or conserve net art. In spite of all these efforts the reality is that many net artworks have already been deleted by their creators, are dysfunctional due to outdated software and network changes, or are unable to perform because of incomplete hardware or hardware that has become obsolete' (Dekker 2014). As the characteristics of a new media artwork are variable and not permanent or fixed, identifying the work's behaviours and strategies can assist curators and conservators in advancing the preservation of the work.

Whereas the accepted norm is to use wall labels, former art museum director, Rudi Fuchs chose to show only the name of the artist and the year in which the artwork was made for his 2017 exhibition, Excitement, of Dutch contemporary artists at the Stedelijk. His decision was motivated by the desire for visitors to view at their own pace and have the freedom to get a feeling for the artworks themselves, not to make sure the label matched the artwork and then move on as is so often the case. Fuchs also believes the artworks do not need a title as many of them are 'untitled' anyway.

The difference between the accompanying documentary labels while viewing an artwork and the documentation required for behind-the-scenes curatorial necessity are distinctively contrasting. A key member of the Variable Media Network, Curator and Conservationist, Caitlin Jones, argues that the centrality of documentary evidence when writing history is invaluable. Her 2008 paper Surveying the state of the art (of documentation) states 'documents related to an artwork can provide us with invaluable information about the production, provenance, exhibition and evolution of the work throughout its life and into the future, and curators, conservators and other researchers rely on it heavily'. She goes on to explain ' ... because it provides information such as the original technological context or artist's intent, it's unfortunate that due to a lack of consistent documentation in the past, we know far too little about many of the landmarks works of new media' (Jones 2008). So, regrettably, while they are not trained to check for the presence of integral components of the artworks, condition checkers will search for flaws in the artworks.

By the use of factual and evaluative documentation, complete checks can be made to reassure curators of preservation strategies for individual artworks. During a residency at the Daniel Langlois Foundation in 2007, Jones and Media Arts Specialist, Paul Kuranko, surveyed the many documentation models currently use individual case studies of individual artworks, including physical models proposed by the DOCAM (Documentation and Conservation of the Media Arts Heritage) Project and theoretical models raised on the CRUMB Discussions List. Although it was never the intention to propose a new model, the Variable Media Questionnaire used a questionnaire to gather information from 
artists and by conducting a series of documentation case studies three distinct phases of documentation were identified:

- collection and creation-data gathered on the conceptual, technical and experiential nature of the work

- arrangement-the structure of the archival arrangement of the work

- description and access-components of artwork and the relationship to the collection as a whole and how the work can be accessed physically or digitally

As NGCA is continually commissioning and collecting artworks, the intention is to work with the artists from the idea to exhibition stages to document all of the above factors while:

- agreeing at the time of commissioning who has the rights to display, market and reproduce the artwork

- documenting interviews with the artist regarding the key issues listed earlier

- documenting the intention of the artist and behaviours and integrity of the artwork so it may not be reproduced or mutated

- capturing images of installation, equipment, components

- documenting interviews with collaborators, technicians and third parties

- compiling data and instructions on manuals and instruction

\subsection{Collecting}

An excellent starting point and another example of the case study approach of experiments and collaborations between collecting institutions, arts agencies and artists is the Harris Museum and Art Gallery, Preston, whose collections include fine art, costume, textiles and archaeology. The Harris was selected as a starting point for this research as at the time of the experiment, they held no new media artworks within their collection and as an Arts Council England accredited institution, their Collections Development Policy must undergo evaluation and agreement by the board of directors prior to any changes in the collecting remit. The Harris is a local authority museum and art gallery which collaborated with a local arts charity to produce Current: an experiment into collecting Digital Art in 2010. Curator at the time, Lindsay Taylor, in Graham, wrote ' ... that the aim of the project was twofold: to celebrate innovative and creative use of digital media technology and to undertake a practical case study for the collection and integration of digital artworks into existing permanent collections' (Graham 2016). By understanding the principles for future and experimental collecting from a traditional, municipal perspective, this model could be translated to a university gallery such as NGCA.

Following research into the Harris' Collections Development Policy, I was led to a Scoping Report written by specialist visual arts advisor, Wendy Law, commissioned by the Harris in 2009. The purpose of the report was 'to support the Harris in developing a nationally significant collection of new media work and to be undertaken in conjunction with the Harris' overall collecting policy, with new media acquisitions being integrated with existing contemporary and historic collections' (Law 2009). The aims and objectives of the 2006 Arts Council England Turning Point long-term strategy to build on existing investment and the success and impact of contemporary visual arts were incorporated into the Scoping Report which was an appendix to the Collections Development Policy at that time. The new media art collection is now housed within the Photography collection which suggests that collecting new media art is still very much in its infancy.

The experiment proved successful with positive and encouraging feedback from visitors and in 2012 was followed by Digital Aesthetic 2, a multi-site exhibition, website and conference curated in partnership between the Harris and the University of Central Lancashire. The Current exhibition curator, Lindsay Taylor, has expertise in curating exhibitions and developing public collections of contemporary art, particularly in areas currently under-represented in museum collections nationally. 
Taylor was the curator at the Harris for the duration of the Current project and invited professionals from Computer Arts Society, Foundation for Art and Creative Technology (FACT) and Tate to be part of the expert panel who would eventually select the artwork to be included in their collection. The chosen artwork was by Thomson and Craighead, The distance travelled through our solar system this year and all the barrels of oil remaining, 2011, which made use of a live internet data stream and tackled environmental issues. Support from the Contemporary Art Society and other agencies demonstrate the success of the project as its legacy lives on and is acknowledged on the museum website that photography, film and video are being used increasingly in contemporary art practice. Taylor is now Curator at the University of Salford Art Collection and has acknowledged in the Collections Development Policy that there is a digital gap in museum collections- often due to concerns about the longevity of the technology required to experience the artwork. As a university it is part of their responsibility to pioneer the collecting of difficult work, to take risks and to find ways of conserving digital artworks, as part of the focus of debate and the evolving cultural infrastructure and landscape. The text below is taken directly from the University of Salford Art Collection Forward Plan 2015-2018:

We are now living in a digital world, and it is important that our art collection reflects some of the excellent artworks made by artists either about or using digital technologies. This gap is recognised in the North West's regional museums' collections-often due to concerns about the longevity of the technology required to experience the artwork. As a university it is part our responsibility to pioneer the collecting of difficult work, to take risks and to find ways of conserving digital artworks, as part of the focus of debate and the evolving cultural infrastructure and landscape. (Taylor 2015)

This strategy could certainly apply to the Collections Development Policy of NGCA as the gallery has given first UK shows to artists such as Kelly Richardson ${ }^{1}$ and Cory Arcangel ${ }^{2}$ several years prior to other galleries acknowledging recognition of the artist. As the gallery commissions work it also collects from the commissioned artists and has a volume of photographic prints as well as new media artworks of various mediums by Graham Dolphin, Dan Holdsworth and Simon Martin. As NGCA comes under the umbrella of Sunderland Culture which also includes National Glass Centre and Sunderland Museum, its specific collecting remit reflects the gallery's commitment to exhibiting and collecting innovative, experimental art.

An interesting model of both collection and distribution was used at the William H. Van Every and Edward M. Smith Galleries at Davidson College, NC, USA. The common university model of display is employed where artworks can be found in campus buildings and loaned to other institutions but recently a giant video wall, usually used for lectures and presentations has found itself the home of new media art by contemporary digital artists initially selected by members of the Art Collection Advisory Committee. The unusual acquisition process involved discussion by gallery interns and stories shared about their favourite artworks which led to public votes on which to acquire. The goal was to foster a sense of community involvement in the acquisition process while celebrating the unique contributions of each artist and work. The Galleries initiated a Give Campus Campaign which raised just over $\$ 7500$ to acquire ten new artworks for the collection. The collection ranges from sixteenth century woodcut prints to the new media artworks recently included into the collection, demonstrating that integration is possible by use of an experimental and innovative approach.

\section{Summing up and Concluding}

As tomorrow's art history is what we are collecting today, the collections become the tools for research, exhibitions, publications and education. With audiences becoming ever-more dependent and

\footnotetext{
Kelly Richardson, Legion. 5 July-29 September 2012, Northern Gallery for Contemporary Art, Sunderland.

2 Cory Arcangel, Couple thousand short films about Glenn Gould. 7 December 2007-26 January 2008, Northern Gallery for Contemporary Art, Sunderland.
} 
aligned to all things networked and digital, which of course makes for easily accessible distribution channels, it is imperative for galleries and institutions to be unafraid of the integration of new media art into their programming and collections to engage with both physical and digital audiences. Collaboration between institutions, transference, distribution of knowledge and an open mind to experimentation are conducive to the integration into collections and henceforth the preservation of new media art. As there are many diverse organisations with their own approaches to collecting, preservation, documentation and distribution it is inevitable that there will be no 'one size fits all' model to inform each of the activities associated with promoting the longevity of new media artworks, although the three basic questions asked when considering a change in the institutional collecting remit should remain the same:

- $\quad$ why do we collect?

- what should we collect?

- how do we acquire what we want?

Although some collecting institutions appear apprehensive when considering acquiring new media art, due to the testing of more experimental and innovative curatorial practices, anxieties can be overcome. The balance must be maintained between ensuring the preservation of the artworks and not impeding on breadth of the artist's creativity. It is true that knowledge, funding, equipment and physical space are integral and essential factors to achieving successful collecting but the evidence outlined in this article advocates that it can be achieved. Taking into account Steve Dietz's categorisation of the three characteristics of new media art, of computability, interactivity and connectivity, it is evident that the title new media art has become an encyclopedic term for an ever expanding and evolving range of creativity and artistic practice. By exploring experimental and innovative practices and having an open minded and progressive approach to curatorial activities has demonstrated that concerns around the assumed complexity of collecting, and distribution can be alleviated. By collecting important data and the detailing of thorough documentation, we can strive to keep new media, digital and networked art from disappearing into obsolescence.

Funding: This research was funded by the Arts and Humanities Research Council (AHRC) and the Northern Productivity Investment Fund (NPIF), UK.

Conflicts of Interest: The author declares no conflict of interest.

\section{References}

Dekker, Annet. 2014. Assembling Traces, or the Conservation of Net Art. Available online: https://necsus-ejms. org/assembling-traces-conservation-net-art/ (accessed on 6 May 2019).

Depocas, Alain. 2003. Goals of the Variable Media Network. In Permanence Through Change: The Variable Media Approach. Edited by Alain Depocas, Jon Ippolito and Caitlin Jones. New York: Guggenheim Museum Publications, p. 7.

Graham, Beryl, ed. 2016. New Collecting: Exhibiting and Audiences after New Media Art. New York: Routledge, pp. 4,118 .

Jones, Caitlin. 2008. Surveying the State of the Art (of Documentation). Available online: http://www.fondationlanglois.org/html/e/page.php?NumPage=2125 (accessed on 6 May 2019).

Kane, Natalie. 2018. Inside the Digital Cube. Spike Art Quarterly 54: 121.

Law, Wendy. 2009. A Scoping Report Collecting New Media Art. Lancashire: Harris Museum and Art Gallery, p. 3.

Paul, Christiane. 2008. New Media in the White Cube and Beyond: Curatorial Models for Digital Art. Oakland: University of California Press, p. 3.

Paul, Christiane. 2015. Digital Art, 3rd ed. London: Thames \& Hudson, p. 25.

Quaranta, Domenico. 2012. What's (Really) Specific about New Media Art? Curating in the Information Age. Available online: http://rhizome.org/editorial/2012/dec/6/whats-really-specific-about-new-media-art-curating/ (accessed on 8 September 2018).

Reichardt, Jasia, ed. 1969. Cybernetic Serendipity: The Computer and the Arts. Santa Barbara: Praeger. 
Serexhe, Bernhard, ed. 2013. Preservation of Digital Art: Theory and Practice. Vienna: Springer, p. 14.

Tate. 2015. Things Change: Conservation and Display of Time-Based Media Art. Available online: https://www.tate. org.uk/about-us/projects/pericles/things-change-conservation-and-display-time-based-media-art (accessed on 6 May 2019).

Taylor, Lindsay. 2015. Forward Plan 2015-2018. Newcastle upon Tyne: University of Salford Art Collection.

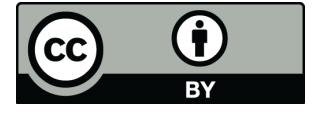

(C) 2019 by the author. Licensee MDPI, Basel, Switzerland. This article is an open access article distributed under the terms and conditions of the Creative Commons Attribution (CC BY) license (http://creativecommons.org/licenses/by/4.0/). 